\title{
THE INFLUENCE OF METEOROLOGICAL CHANGES ON CORONARY THROMBOSIS
}

\author{
BY \\ A. O. ADESOLA \\ From the Royal Victoria Hospital, Belfast \\ Received January 13, 1960
}

The present study represents an analysis of all patients admitted to the Royal Victoria Hospital, Belfast, during the period 1953 to 1956 inclusive. The object was to determine the incidence and mortality in relation to sex, age, and the blood pressure on admission and in particular in relation to climatic factors. The influence of weather was especially studied, because of an impression that the admission rate varied with the time of year, a feature that has been reported previously (Teng and Heyer, 1955), but inadequately studied.

\section{METHODS}

The records of all patients admitted as coronary thrombosis or myocardial infarction during the period 1953 to 1956 inclusive were reviewed and in addition meteorological data for the City of Belfast were obtained from the Meteorological Observatory of Queen's University of Belfast. In each case details of age, sex, blood pressure on admission, address, date of infarction, activity at the time of infarction, and ultimate fate were recorded. Where there was a history of more than one attack, only the details of the first were taken. There were in all 390 cases, but 30 of these were excluded, because they lived outside Belfast, where no meteorological information was available. In a further 62 cases the records were incomplete in one or more respects: these were excluded from the study apart from certain comparisons, for which data were available. In only 126 cases were the activities of the patients at the time of onset of myocardial infarction recorded.

There is no reason to believe that the patients for whom data were incomplete differed in any way from the rest. Also, the system of admissions in the Belfast area would justify the assumption that the admissions of patients with coronary disease into the Royal Victoria Hospital are typical of those of all general hospitals in Belfast.

Summary of Statistical Techniques. In this report the frequency of admissions of patients with coronary thrombosis has been examined in relation to age and sex, daily, monthly, and seasonal variations, and also in relation to the possible influences of meteorological changes. The immediate mortality of these cases has also been examined with regard to age and blood pressure on admission.

Throughout this report these observed frequencies have been tested against frequencies expected by particular hypotheses by means of the $\chi^{2}$ test. The hypotheses on which the expected values are calculated vary for the different variables given above. For example, the observed number of admissions on each day of the week was compared with that expected on the hypothesis that, if there was no variation with the day of the week, then admissions would be expected to occur with equal frequency (i.e. on any one day one-seventh of the total admissions). The expected values for monthly and seasonal distributions of admission were calculated on similar hypotheses. 
The expected distribution of admissions at a specific minimum temperature was calculated on the hypothesis that a number of admissions on any day with a given minimum temperature was directly proportional to the number of days on which that given minimum temperature was recorded (i.e. if $x$ per cent of all days in the period 1953 to 1956 had a given minimum temperature, then $x$ per cent of all admissions would be expected to have occurred on days having the given minimum temperature). Similar hypotheses enabled the expected distributions of admissions for maximum temperature, maximum-minimum temperature deviation, barometric pressure, and relative humidity to be calculated.

Where possible all of the variables mentioned earlier have been studied in relation to four age groups. $\chi^{2}$ was thus calculated for each variable irrespective of age and the probability obtained. A test of heterogeneity was then applied, when the expected numbers were large enough for $\chi^{2}$ to be calculated, to assess where the results obtained for all ages combined, in fact, apply equally to each of the four age groups.

Throughout the report, a value of $P<0.05$ is regarded as significant.

\section{RESULTS}

In this series of 298 cases there were 223 men and 75 women; a ratio of $3: 1$ (Table I).

TABLE I

Age and Sex Distribution of 298 Cases of Coronary Thrombosis Admitted to the Royal Victoria Hospital, Belfast, 1953 to 1956

\begin{tabular}{|c|c|c|c|c|c|c|c|c|c|}
\hline \multirow{3}{*}{ Sex } & \multicolumn{8}{|c|}{ Age groups } & \multirow{3}{*}{ Total } \\
\hline & \multicolumn{2}{|c|}{ Under 50} & \multicolumn{2}{|c|}{$50-59$} & \multicolumn{2}{|c|}{$60-69$} & \multicolumn{2}{|c|}{70 and over } & \\
\hline & Observed & Expected & Observed & Expected & Observed & Expected & Observed & Expected & \\
\hline Men & $\begin{array}{c}49 \\
(83 \%)\end{array}$ & $44 \cdot 2$ & $\begin{array}{c}81 \\
(84 \%)\end{array}$ & $71 \cdot 8$ & $\begin{array}{c}67 \\
(68 \%)\end{array}$ & $73 \cdot 3$ & $\begin{array}{c}26 \\
(58 \%)\end{array}$ & $33 \cdot 7$ & $\begin{array}{c}223 \\
(75 \%)\end{array}$ \\
\hline Women & $\begin{array}{c}10 \\
(17 \%)\end{array}$ & $14 \cdot 8$ & $\begin{array}{c}15 \\
(16 \%)\end{array}$ & $24 \cdot 2$ & $\begin{array}{c}31 \\
(32 \%)\end{array}$ & $24 \cdot 7$ & $\begin{array}{c}19 \\
(42 \%)\end{array}$ & $11 \cdot 3$ & $\begin{array}{c}75 \\
(25 \%)\end{array}$ \\
\hline Total & \multicolumn{2}{|c|}{$\begin{array}{c}59 \\
(20 \%)\end{array}$} & \multicolumn{2}{|c|}{$\begin{array}{c}96 \\
(32 \%)\end{array}$} & \multicolumn{2}{|c|}{$\begin{array}{c}98 \\
(33 \%)\end{array}$} & \multicolumn{2}{|c|}{$\begin{array}{c}45 \\
(15 \%)\end{array}$} & 298 \\
\hline
\end{tabular}

$\chi^{2}$ (based on absolute numbers) $=17 \cdot 4$

Degrees of freedom $=3$

$P<0.001$

As will be seen from Tables II and III no significant differences were noted between the observed and expected admission for any particular day of the week or season of the year. Maximum temperature on the day of infarction did not appear to influence the admission rate $(0 \cdot 2>P>0 \cdot 1)$ and in the same way the effect of maximum to minimum temperature range was insignificant $(0.8>P>0.7)$. At a higher relative humidity there appeared to be fewer admissions as compared with the expected number of cases $(0.05>P>0.02)$.

The patient's age (Table IV), systolic blood pressure (Table Va), and diastolic blood pressure (Table $\mathrm{Vb}$ ) on admission appeared to have a significant effect on the immediate mortality.

Of 126 cases, whose activities at the time of infarction were known, $58(46 \%)$ had attacks while asleep or at complete rest (Table VI).

As will be seen from Table VII, barometric pressure did not appear to have a significant effect on the admission rate. When considered in relation to the four age groups under study, a rise in 
TABLE II

Frequency Distribution of Cases of Myocardial Infarction Admitted on Different Days of the Week to the Royal Victoria Hospital, Belfast, from 1953 to 1956

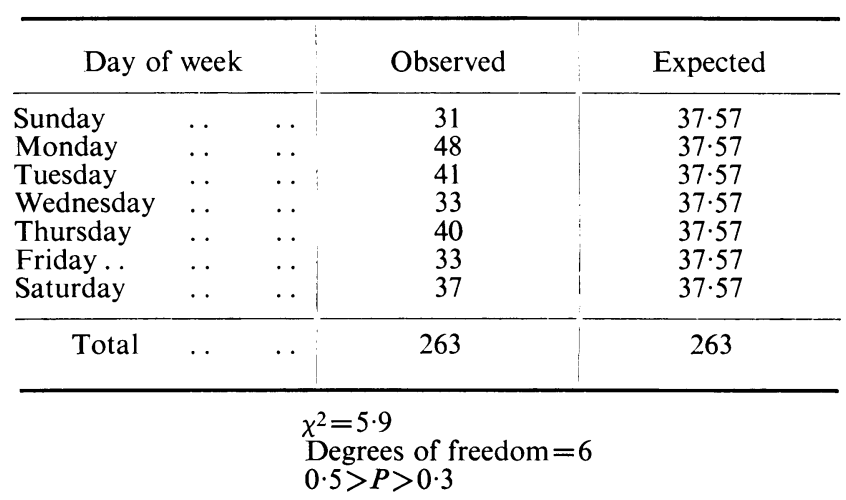

A test of heterogeneity shows this result applies to the various age groups studied.

TABLE III

Frequency Distribution of Cases of Acute Myocardial Infarction Admitted to the Royal Victoria Hospital, Belfast, DURing the Various Seasons, from 1953 to 1956

\begin{tabular}{|c|c|c|c|}
\hline Months & & Observed & Expected \\
\hline December, January, February & . & 85 & $71 \cdot 6$ \\
\hline March, April, May .. & . & 76 & $78 \cdot 1$ \\
\hline June, July, August . . & . & 77 & $78 \cdot 1$ \\
\hline September, October, November & . & 55 & $65 \cdot 2$ \\
\hline Total & $\ldots$ & 293 & 293 \\
\hline
\end{tabular}

$\chi^{2}=4 \cdot 15$

Degrees of freedom $=3$

$0 \cdot 30>P>0 \cdot 20$

A test of heterogeneity shows this result applies to the various age groups studied.

TABLE IV

Immediate Mortality in Relation to Age, of 297 Cases of Acute Myocardial INFARCTION ADMITTEd to Royal Victoria Hospital, Belfast, FROM 1953 to 1956

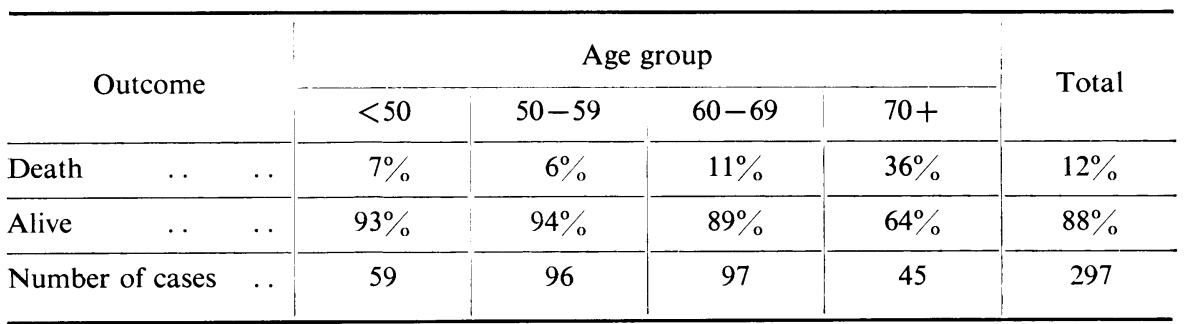

$\chi^{2}$ (based on absolute numbers only) $=27 \cdot 3$

Degrees of freedom $=3$

$P<0.001$ 
TABLE Va

Relationship between Immediate Mortality and Systolic Blood Pressure on ADMISSION

\begin{tabular}{|c|c|c|c|c|c|c|c|}
\hline \multirow{2}{*}{\multicolumn{2}{|c|}{ Outcome }} & & \multicolumn{4}{|c|}{$\begin{array}{l}\text { Systolic blood pressure } \\
\text { (mm. Hg) }\end{array}$} & \multirow[t]{2}{*}{ Total } \\
\hline & & & $<110$ & $110-129$ & $130-149$ & $150+$ & \\
\hline Death & . & . & $36 \%$ & $11 \%$ & $10 \%$ & $7 \%$ & $12 \%$ \\
\hline Alive & . & . & $64 \%$ & $89 \%$ & $90 \%$ & $93 \%$ & $88 \%$ \\
\hline \multicolumn{3}{|c|}{ Number of cases } & 39 & 57 & 79 & 121 & 296 \\
\hline
\end{tabular}

$\chi^{2}$ (based on absolute numbers, not percentages) $=23$ Degrees of freedom $=3$ $P<0.001$

TABLE Vb

Relationship between Immediate Mortality and Diastolic Blood Pressure on ADMISSION

\begin{tabular}{|c|c|c|c|c|c|c|c|}
\hline \multirow{2}{*}{\multicolumn{2}{|c|}{ Outcome }} & & \multicolumn{4}{|c|}{$\begin{array}{l}\text { Diastolic blood pressure } \\
(\mathrm{mm} . \mathrm{Hg})\end{array}$} & \multirow{2}{*}{ Total } \\
\hline & & & $<80$ & $80-89$ & $90-99$ & $100+$ & \\
\hline Death & $\ldots$ & . & $22 \%$ & $8 \%$ & $9 \%$ & $11 \%$ & $12 \%$ \\
\hline Alive & $\cdots$ & $\cdots$ & $78 \%$ & $92 \%$ & $91 \%$ & $89 \%$ & $88 \%$ \\
\hline \multicolumn{3}{|c|}{ Number of cases } & 72 & 64 & 69 & 91 & 296 \\
\hline
\end{tabular}

$\chi^{2}$ (based on absolute numbers, not percentages) $=8 \cdot 6$ Degrees of freedom $=3$ $0.05>P>0.02$

TABLE VI

Mode of Onset of 126 Cases of Acute Myocardial Infarction, Admitted to ROYAl Victoria HOSPITAL, BELFAST, FROM 1953 TO 1956 INCLUSIVE

\begin{tabular}{|c|c|c|}
\hline Mode of onset & $\begin{array}{l}\text { Number of cases } \\
\text { (Total) }\end{array}$ & $\begin{array}{c}\text { Number of cases } \\
\text { (Percentage) }\end{array}$ \\
\hline 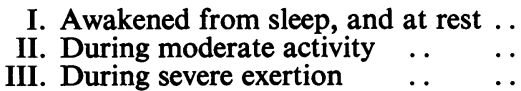 & $\begin{array}{l}58 \\
51 \\
17\end{array}$ & $\begin{array}{l}46 \\
40 \\
14\end{array}$ \\
\hline
\end{tabular}

the barometric pressure appeared to increase significantly the admission rate of the older patients, mainly from 60 years onwards $(0.01>P>0.001)$. This result is confirmed by applying the heterogeneity test $(0.01>P>0.001)$.

A fall in the minimum temperature (Table VIII) appeared to increase the admission rate. This result remains significant irrespective of the age groups, and is particularly consistent at minimum temperature ranges below $40^{\circ} \mathrm{F}$. An attempt was made to assess the effects of the two variables (barometric pressure and minimum temperature) when the other was held constant; e.g. during the 160 days when barometric pressure was $1005 \mathrm{~mm}$. $\mathrm{Hg}-1009 \mathrm{~mm}$. $\mathrm{Hg} 35$ cases were admitted. For 4 of the 160 days the maximum temperature was $25^{\circ} \mathrm{F} .-29^{\circ} \mathrm{F}$; therefore, we should expect $4 / 160$ of these 35 cases to have been admitted when the temperature was $25^{\circ} \mathrm{F}$. $-29^{\circ} \mathrm{F}$., on the hypothesis 
TABLE VII

Frequency Distribution of Cases of Acute Myocardial Infarction at Different Ranges of Barometric Pressure (Minimum Temperature not Constant) in Belfast (See text for explanation of method)

\begin{tabular}{|c|c|c|}
\hline $\begin{array}{l}\text { Barometric } \\
\text { pressure }\end{array}$ & $\begin{array}{l}\text { Observed number } \\
\text { of cases }\end{array}$ & $\begin{array}{l}\text { Expected number } \\
\text { of cases }\end{array}$ \\
\hline $\begin{array}{l}\text { Under } 1000 \\
\begin{array}{l}1000-09 \\
1010-19 \\
1020 \text { and over }\end{array}\end{array}$ & $\begin{array}{l}41 \\
56 \\
75 \\
65\end{array}$ & $\begin{array}{l}37 \cdot 6 \\
53 \cdot 4 \\
80 \cdot 4 \\
65 \cdot 6\end{array}$ \\
\hline Total $\quad \ldots$ & 237 & 237 \\
\hline & \multicolumn{2}{|c|}{$\begin{array}{l}\chi^{2}=0.79 \\
\text { Degrees of freedom }=3 \\
0.90>P>0.80\end{array}$} \\
\hline & \multicolumn{2}{|c|}{$\begin{array}{l}\text { For four age groups } \\
\text { Total } \chi^{2}=26 \cdot 27 \\
\text { Degrees of freedom }=12 \\
0.01>P>0.001\end{array}$} \\
\hline
\end{tabular}

A test of heterogeneity shows this result remains significant for the age groups $60-$ and $70+$.

TABLE VIII

Frequency Distribution of Cases of Acute Myocardial INFARCTION AT DifFERENT RANGeS OF MiNiMUM TEMPERATURE (BAROMetric Pressure nOt Constant) in Belfast (See text for explanation of method)

\begin{tabular}{c|c|c}
\hline $\begin{array}{c}\text { Minimum } \\
\text { temperature* }\end{array}$ & $\begin{array}{c}\text { Observed number } \\
\text { of cases }\end{array}$ & $\begin{array}{c}\text { Expected number } \\
\text { of cases }\end{array}$ \\
\hline Under 35 & 44 & $34 \cdot 5$ \\
$35-39$ & 37 & $38 \cdot 4$ \\
$40-44$ & 70 & $48 \cdot 7$ \\
$45-49$ & 35 & $45 \cdot 3$ \\
50 and over & 51 & $70 \cdot 1$ \\
\hline Total . & 237 & 237 \\
\hline
\end{tabular}

\footnotetext{
* In degrees Fahrenheit.

Total $\chi^{2}=19 \cdot 6$

Degrees of freedom $=4$

$P<0.001$
}

A test of heterogeneity shows this result applies to the various age groups.

that for a given barometric pressure, there was no association between admission rate and temperature. Similar calculations were made for each temperature group, and the whole process repeated for each barometric pressure group. The expected distributions of admissions thus obtained were compared with the observed distributions of admissions.

The result shows that when the barometric pressure is constant, the minimum temperature remains significant (Table IX), but when the minimum temperature is constant, the barometric pressure no longer has a significant effect on the admission rate. No significant correlation was 
TABLE IX

Frequency Distribution of Cases of Acute Myocardial INFARCTION AT DIFFERENT RANGES OF MINIMUM TEMPERATURE holding Barometric Pressure Constant, in Belfast

(See text for explanation of method)

\begin{tabular}{|c|c|c|}
\hline $\begin{array}{l}\text { Minimum } \\
\text { temperature* }\end{array}$ & $\begin{array}{l}\text { Observed number } \\
\text { of cases }\end{array}$ & $\begin{array}{l}\text { Expected number } \\
\text { of cases }\end{array}$ \\
\hline $\begin{array}{l}20-29 \\
30-34 \\
35-39 \\
40-44 \\
45-49 \\
50-54 \\
55 \text { and over }\end{array}$ & $\begin{array}{l}19 \\
25 \\
37 \\
70 \\
35 \\
35 \\
16\end{array}$ & $\begin{array}{l}10 \cdot 7 \\
22 \cdot 9 \\
38 \cdot 7 \\
49 \\
45 \cdot 9 \\
50 \\
19 \cdot 8\end{array}$ \\
\hline Total .. . & 237 & 237 \\
\hline
\end{tabular}

found between barometric pressure and minimum temperature $(\mathrm{r}=0 \cdot 006,1289$ degrees of freedom, $P>0 \cdot 05)$.

\section{Discussion}

Some of the findings confirm generally held beliefs: for example, in this series men were affected more than women in the ratio of $3: 1$. Also, infarction occurred at a younger age group in men.

Mortality. There were 35 deaths $(12 \%)$, and more deaths occurred in the older age groups. A point of some practical importance in the management of these patients is that 90 per cent of the deaths occurred within the first 15 days of admission. It is clear that the maximum therapeutic effort should be devoted to this period.

The immediate prognosis is worse in those patients with low systolic blood pressure on admission. For example, in patients with systolic blood pressure below $110 \mathrm{~mm}$. $\mathrm{Hg}$ the mortality was 36 per cent, while it was only 7 per cent in patients admitted with systolic blood pressure of 150 $\mathrm{mm}$. Hg and over. These results confirm the findings of Shillito et al. (1942).

Relative Humidity. A rise in the relative humidity appeared to increase the incidence of coronary thrombosis. Humidity changes have been reported to affect patients with heart disease, particularly in tropical and subtropical climates (Burch, 1946).

Barometric Pressure. Examination of the crude data shows a significant correlation between barometric pressure and the frequency of occurrence of myocardial infarction. On further analysis, where the minimum temperature is held constant, the barometric pressure ceases to be a significant factor. The relationship, therefore, is regarded as only an indirect one.

Minimum Temperature. Generally, as the minimum temperature falls, the admission rate increases. This inverse relationship remains significant, both on examination of the crude data and on further analysis where the barometric pressure is constant.

A relationship between changes in weather and heart disease has been reported by previous workers (Brown and Pearson, 1948; Teng and Heyer, 1955). At present not much is known about the mechanisms by which meteorological changes affect patients with coronary heart disease.

Although the basic pathology in coronary thrombosis is coronary atherosclerosis, myocardial infarction and atherosclerosis should not be regarded as simple functions one of the other (Morris and Dale, 1955). 
Physical exertion is sometimes regarded as a stress factor that may precipitate myocardial infarction in patients with coronary heart disease. In 126 cases the activities of the patients at the time of onset of the infarct were known (Table VI); and $58(46 \%)$ had their attacks while asleep or at complete rest. Physical exertion, in this group, therefore is not an important factor. Also, no particular concentration of first attacks was noted on any day of the week.

Lowering of the external temperature within a given range increases the rate of tissue metabolism (Mills, 1939). This may put a strain on the heart, which thus suffers varying degrees of hypoxia. Exposure to cold produces vasoconstriction, which probably increases the work load of the heart. Blood pressures in normal or hypertensive subjects is said to fall by about 30 per cent of the pre-existing winter levels in summer and autumn, due probably to loss of vascular spasm (Mills, 1939).

Halse and Quennet (1948) found that hyperprothrombinæmia and thrombo-embolism occurred with a drop in barometric pressure. It is possible that such relationship is only an indirect one, and that temperature plays an important part here. If this proves to be the case, then we have here a possible explanation of the findings in the present study.

Myocardial damage has been observed in dogs in association with experimental hypothermia (Sarajas et al., 1956). Bigelow et al. (1950) noted that during progressive cooling, there is an increasing aggregation of red cells in the peripheral vascular bed, resulting in complete cessation of capillary blood flow. No conclusions can yet be drawn from these findings; nor do the experiments necessarily explain how myocardial infarction is produced in man at moderately low temperatures.

\section{SummaRY AND CONCLUSIONS}

A brief statistical survey was made of cases admitted as coronary thrombosis to the Royal Victoria Hospital, Belfast, from 1953 to 1956. A possible relationship between weather changes and the onset of acute myocardial infarction was investigated.

A higher mortality was noted in the older age groups; it would appear from this study that the lower the blood pressure on admission, the less favourable the immediate prognosis. Most deaths occurred within 15 days of admission and the first few days may be regarded as the "critical period" of this disease.

An increased frequency of occurrence of acute myocardial infarction was noted during periods of low minimum temperatures. It appears from this study that the onset of cold weather may precipitate attacks of acute myocardial infarction in patients with coronary heart disease.

I wish to thank Professor G. M. Bull for his most valuable advice and encouragement, and Dr. Cheeseman for his advice in the preparation and analysis of the statistical data. I am also indebted to Mrs. McCabe, Mr. Merrett, and Miss Weller for technical assistance.

\section{REFERENCES}

Bigelow, W. G., Lindsay, W. K., and Greenwood, W. F. (1950). Ann. Surg., 132, 849.

Brown, H. R., Jr., and Pearson, R. (1948). Amer. Heart J., 35, 763.

Burch, G. E. (1946). Amer. J. med. Sci., 211, 181.

Halse, T., Jr., and Quennet, G. (1948). Dtsch. med. Wschr., 73, 125.

Mills, C. A. (1939). Amer. J. Hyg., 29, 147.

Morris, J. N., and Dale, R. S. (1955). Proc. roy. Soc. Med., 48, 667.

Sarajas, H. S. S., Senning, A., and Kaplan, J. (1956). Amer. Heart J., 52, 836.

Shillito, F. H., Chamberlain, F. L., and Levy, R. L. (1942). J. Amer. med. Ass., 118, 779.

Teng, H. C., and Heyer, H. E. (1955). Amer. Heart J., 49, 9. 